\title{
More metastases - incidence increased in the USA
}

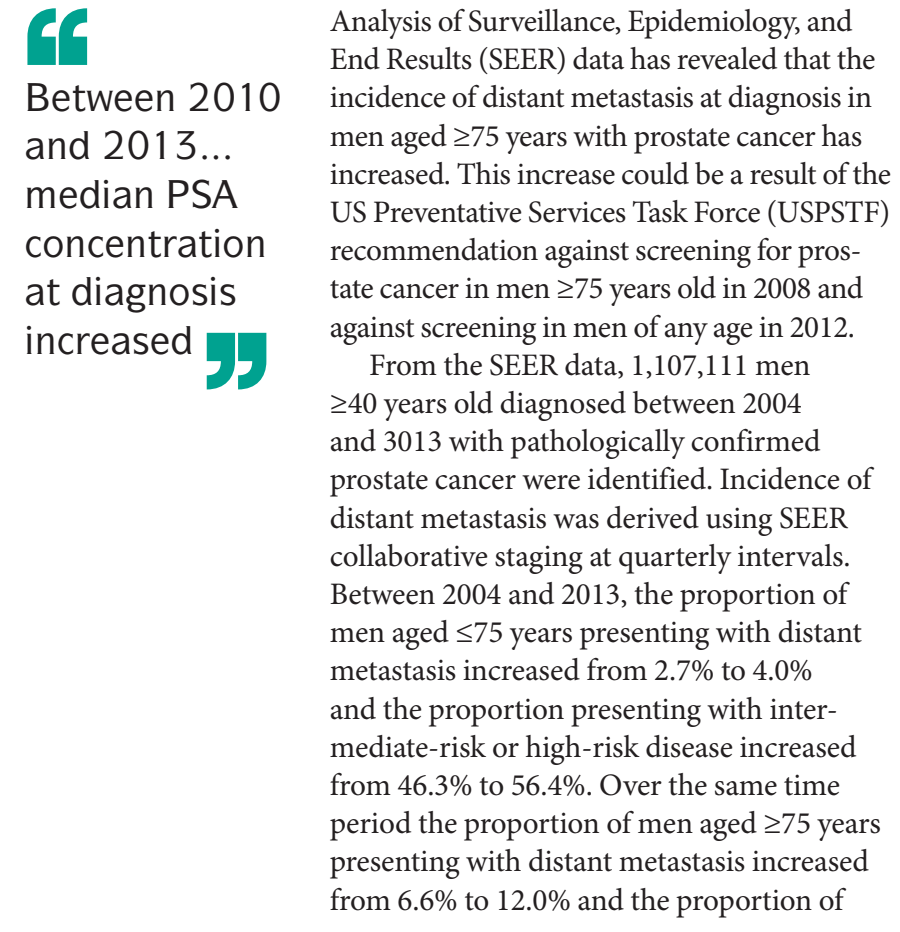

those presenting with intermediate-risk or high-risk disease increased from $58.1 \%$ to 72.0\%. Between 2010 and 2013, for which data on serum PSA characteristics were available, median PSA concentration at diagnosis increased from $6.0 \mathrm{ng} / \mathrm{ml}$ to $6.4 \mathrm{ng} / \mathrm{ml}$ in men aged $\leq 75$ years old, and from $9.0 \mathrm{ng} / \mathrm{ml}$ to $9.7 \mathrm{ng} / \mathrm{ml}$ in men $\geq 75$ years old. Furthermore, a decrease in the incidence of distant metastasis at diagnosis in men $\geq 75$ years old was observed from 2004 to 2011, but from 2011 to 2013, incidence increased.

The significant increase in the incidence of distant metastasis at prostate cancer diagnosis in men aged $\geq 75$ years between 2011 and 2013 in men in could be an effect of the USPSTF 2008 recommendation against screening for prostate cancer in these men.

Louise Stone

ORIGINAL ARTICLE Hu, J. C. et al. Increase in prostate cancer distant metastases at diagnosis in the United States. JAMA Oncol. http://dx.doi.org/10.1001/jamaoncol.2016.5465 (2016) 